\title{
Aplicação foliar de nitrogênio em diferentes estádios fenológicos na cultura da soja
}

\author{
Adenilson Carlos PINTO ${ }^{*}$, Rafael ZAMBENEDETTI ${ }^{1}$, Alex Junior Cavalcante de OLIVEIRA ${ }^{1}$, \\ Cassiano Spaziani PEREIRA¹, Adriano Alves da SILVA²
}

\author{
${ }^{1}$ Programa de Pós-Graduação em Agronomia, Universidade Federal de Mato Grosso, Sinop, MT, Brasil. \\ (ORCID: *; 0000-0001-8793-580X; 0000-0001-6781-1228; 0000-0002-2001-697X) \\ ${ }^{2}$ Centro Universitário de Formiga, UNIFOR-MG, Formiga, MG, Brasil. (ORCID: 0000-0002-9863-839X) \\ *E-mail: adenilson7calros@gmail.com (ORCID: 0000-0002-3911-6890)
}

Recebido em 20/06/2019; Aceito em 07/05/2020; Publicado em 29/05/2020.

\begin{abstract}
RESUMO: A inoculação é a principal forma de suprimento de $\mathrm{N}$ na cultura de soja no Brasil. O objetivo deste estudo foi avaliar os efeitos da adubação nitrogenada via foliar em diferentes estádios na cultura da soja. O trabalho foi conduzido em blocos casualizados (DBC) com nove tratamentos. A testemunha não recebeu adubação foliar, apenas inoculação pelas bactérias via sementes; os outros tratamentos receberam $10 \mathrm{~kg} / \mathrm{ha}$ de $\mathrm{N}$ na forma de ureia nos estádios fenológicos $V_{2}, V_{4}, V_{6}, V_{8}, R_{1}, R_{2}, R_{3}$ e $R_{4}$ via foliar. A cultivar utilizada foi a Desafio RR. No estádio $\mathrm{R}_{5}$ avaliaram-se o índice de clorofila, a área foliar, o número de folhas, o número de nódulos, a matéria seca dos nódulos, a matéria seca das raízes, a matéria seca das partes aéreas e o diâmetro do caule. Na maturação fisiológica determinaram-se os componentes de produtividade, altura de plantas, o número de vagens, o número de grãos por vagens, a massa de 1000 grãos e a produtividade. A aplicação de nitrogênio só ocorreu incremento na fase inicial estádio $\mathrm{V}_{2}$. Portanto o maior rendimento de produtividade ocorre quando se aplica $\mathrm{N}$ no estádio $\mathrm{V}_{2}$, no entanto, na composição entre elas, não justifica o retorno financeiro.
\end{abstract}

Palavras-chave: adubação nitrogenada; nutrição foliar; rendimento.

\section{Foliar application of nitrogen in different phenological stages in soybean culture}

\begin{abstract}
Inoculation is the main form of $\mathrm{N}$ supply in soybean culture in Brazil. The aim of this study was to evaluate the effects of nitrogen fertilization via leaf at different stages in soybean culture. The work was carried out in randomized blocks (DBC) with nine treatments. The control did not receive foliar fertilization, only inoculation by bacteria via seeds; the other treatments received $10 \mathrm{~kg} / \mathrm{ha}$ of $\mathrm{N}$ as urea in the phenological stages $V_{2}, V_{4}, V_{6}, V_{8}, R_{1}, R_{2}, R_{3}$ and $R_{4}$ via leaf. The cultivar used was Desafio RR. At the $R_{5}$ stage, the chlorophyll index, leaf area, number of leaves, number of nodules, dry matter of nodules, dry matter of roots, dry matter of aerial parts and stem diameter were evaluated. In the physiological maturation, the components of productivity, plant height, the number of pods, the number of grains per pod, the mass of 1000 grains and the productivity were determined. The nitrogen application only increased in the initial stage $\mathrm{V}_{2}$. Therefore, the highest productivity yield occurs when $\mathrm{N}$ is applied at stage $\mathrm{V}_{2}$, however, in the composition between them, it does not justify the financial return.
\end{abstract}

Key words: nitrogen fertilization; leaf nutrition; yield.

\section{INTRODUÇÃO}

A produção de grãos, no Brasil, na safra 2018/2019, atingiu 235 milhões de toneladas, um recorde, sendo a soja o grão mais produzido no Brasil com produção de 114 milhões de toneladas (CONAB, 2019). Entretanto, muitos problemas estão reduzindo a produtividade da soja, e o principal deles é a deficiência nutricional que pode surgir.

A área semeada em Mato Grosso aumenta a cada ano, e essas novas áreas normalmente estão degradadas ou foram abertas e estão iniciando o cultivo da oleaginosa. Mas a que se deve o interesse mundial pela soja? Em grande parte, esse interesse é devido ao teor elevado de proteína de seus grãos, cerca de $40 \%$, constituindo uma fonte importante para a alimentação humana e para os animais. Um componente essencial das proteínas é o nitrogênio $(\mathrm{N})$, o que faz com que a cultura necessite de grandes quantidades desse nutriente (CRISPINO et al., 2001).

Nesse sentido, o teor elevado de proteína dos grãos de soja resulta em uma demanda de nitrogênio $(\mathrm{N})$ de $65 \mathrm{~kg}$ de $\mathrm{N}$ para a produção de $1.000 \mathrm{~kg}$ de grãos, devendo-se adicionar, a isso, aproximadamente $15 \mathrm{~kg}$ de $\mathrm{N}$ para a produção de folhas, caules e raízes, resultando em um total de $80 \mathrm{~kg}$ de N (PÍPOLO et al., 2015). Consequentemente, rendimentos de $3.000 \mathrm{~kg} / \mathrm{ha}$ implicam a necessidade de 240 $\mathrm{kg}$ de N (HUNGRIA et al., 2001).

A soja é, portanto, uma cultura que apresenta grande demanda de nutrientes, especialmente o nitrogênio, sendo este extraído predominantemente através da fixação biológica por bactérias fixadoras de nitrogênio atmosférico $\mathrm{N}_{2}$ (Bradyrbizobium japonicum e B. elkanii), as quais fornecem 
eficientemente para os grãos de soja cerca de $150 \mathrm{Kg} \mathrm{ha}^{-1}$ de nitrogênio (HUNGRIA et al., 2007).

A aplicação de $\mathrm{N}$ na soja ainda é muito discutida por diversos autores, pois, se, por um lado, tem-se o nutriente prontamente disponível para as plantas, por outro, existe um antagonismo $\mathrm{N}$ x nodulação, além do custo/benefício em realizar a aplicação que nem sempre é viável (PÍPOLO et al., 2015).

Entretanto, alguns autores como Sfredo; Oliveira (2010) relatam que, com o melhoramento genético, as cultivares têm-se tornado mais produtivas, exigentes em nutrientes e exigido a complementação da FBN com adubação mineral para atingir o maior potencial de produtividade da cultura.

Desse modo, o objetivo do trabalho foi verificar em qual estádio fenológico existe melhor resposta à adubação nitrogenada foliar.

\section{MATERIAL E MÉTODOS}

O experimento foi conduzido em uma área de cultivo comercial localizada no município de Sinop - MT, de latitude $11^{\circ} 57^{\prime} 05^{\prime \prime} \mathrm{S}$, longitude $55^{\circ} 23^{\prime} 51^{\prime \prime} \mathrm{O}$ e altitude de aproximadamente $380 \mathrm{~m}$, com topografia plana (SOUZA et. al., 2013), entre novembro de 2017 e janeiro de 2018, em sistema de plantio direto há sete anos. O clima local é classificado com Aw segundo Koppen-Geiger, com precipitação média anual de 2100 milímetros e amplitude térmica de $24^{\circ} \mathrm{C}$ a $27^{\circ} \mathrm{C}$.

O solo da região é classificado como Latossolo Vermelho Amarelo (EMBRAPA, 2018). Antes da instalação do experimento, realizou-se uma amostragem de solo na camada de 0 a 20 centímetros. Após a coleta, a amostra foi encaminhada para o laboratório para análise química e física (Tabela 1). Com a análise de solo, realizaram-se a interpretação e recomendação de adubação, que foi realizada a lanço em todas as parcelas do experimento. Antes da semeadura, foram feitos o tratamento de sementes e a inoculação comercial com inoculante turfoso com a presença de duas bactérias: Bradyrhizobium japonicum e B. elkanii.

TABELA 1. Análise granulométrica e fertilidade do Latossolo Vermelho-Amarelo distrófico na camada de $0-0,20 \mathrm{~m}$ de profundidade ${ }^{(1)}$.

TABLE 1. Particle size and fertility analysis of the dystrophic RedYellow Latosol in the $0-0.20 \mathrm{~m}$ depth layer ${ }^{(1)}$.

\begin{tabular}{cccccc}
\hline $\mathrm{pH}$ & $\mathrm{P}$ & $\mathrm{K}$ & $\mathrm{Ca}$ & $\mathrm{Mg}$ & $\mathrm{H}+\mathrm{Al}$ \\
4,6 & 8,89 & 50 & 1,81 & 0,20 & 4,75 \\
\hline $\mathrm{T}$ & $\mathrm{V}$ & $\mathrm{MO}$ & $\mathrm{ARE}$ & $\mathrm{SIL}$ & $\mathrm{ARG}$ \\
6,90 & 31,11 & 18,68 & 341 & 167 & 492 \\
\hline $\mathrm{Zn}$ & $\mathrm{Cu}$ & $\mathrm{Fe}$ & $\mathrm{Mn}$ & $\mathrm{B}$ & $\mathrm{S}$ \\
4,10 & 0,56 & 105,39 & 4,11 & 0,19 & 13,81
\end{tabular}

(1) $\mathrm{pH}$ em CaCl2; P: fósforo disponível Mehlich-1 $\left(\mathrm{mg} \mathrm{dm}^{-3}\right), \mathrm{K}$ : potássio Mehlich-1 $\left(\mathrm{mg} \mathrm{dm}^{-3}\right)$, Ca: cálcio $\left(\mathrm{cmolc}_{\mathrm{c}} \mathrm{dm}^{-3}\right)$, Mg: magnésio $\left(\mathrm{cmolc}_{\mathrm{c}} \mathrm{dm}^{-3}\right)$, $\mathrm{H}+\mathrm{Al}$ : acidez potencial $\left(\mathrm{cmol}_{\mathrm{c}} \mathrm{dm}^{-3}\right)$, T: capacidade de troca catiônica a $\mathrm{pH}$ $7\left(\mathrm{cmol}_{\mathrm{c}} \mathrm{dm}^{-3}\right)$, V: saturação por bases (\%), MO: matéria orgânica $\left(\mathrm{g} \mathrm{kg}^{-1}\right)$, ARE: areia $\left(\mathrm{g} \mathrm{kg}^{-1}\right)$, SIL: silte $\left(\mathrm{g} \mathrm{kg}^{-1}\right)$ e ARG: argila $\left(\mathrm{g} \mathrm{kg}^{-1}\right)$; Zn: Mehlich-1 ( $\left.\mathrm{mg} \mathrm{dm}^{-3}\right)$; Cu: Mehlich-1 (mg dm ${ }^{-3}$; Fe: Mehlich-1 ( $\left.\mathrm{mg} \mathrm{dm}^{-3}\right)$; Mn: Mehlich1 ( $\left.\mathrm{mg} \mathrm{dm}^{-3}\right)$; B: em CaCl2; S: Fosfato de cálcio.

O delineamento foi em blocos casualizados (DBC) com quatro repetições e nove tratamentos, totalizando 36 parcelas. A testemunha não recebeu $\mathrm{N}$ (somente o nitrogênio fornecido pelas bactérias inoculadas). Todos os demais tratamentos receberam dose de $10 \mathrm{~kg} /$ ha de $\mathrm{N}$ (ureia $45 \%$ de $\mathrm{N})$ correspondentes a $22,5 \mathrm{~kg}$ de ureia por hectare, em diferentes estádios fenológicos a saber: $V_{2}, V_{4}, V_{6}$ e $V_{8}$ no vegetativo. Já no período reprodutivo, as doses foram aplicadas em $\mathrm{R}_{1}, \mathrm{R}_{2}, \mathrm{R}_{3}$ e $\mathrm{R}_{4}$.

As parcelas foram constituídas de 6 linhas de 5 metros de comprimento, totalizando 15 metros quadrados por parcela. A semeadura foi realizada com espaçamento entrelinhas de 50 centímetros, de forma que cada parcela abrigou 5 linhas. As duas linhas laterais (bordaduras) não foram utilizadas para coleta de dados, sendo descartadas juntamente com 50 centímetros das extremidades das linhas uteis, de modo que a área útil da parcela foi de 8 metros quadrados.

As aplicações dos tratamentos foram realizadas nos estádios citados anteriormente, ao final do dia, em condições de temperaturas amenas, com o auxílio de uma bomba costal de 20 litros. A calda foi preparada no momento da aplicação utilizando copos medidores e uma balança de bancada. Foram utilizados, por repetição, $600 \mathrm{ml}$ de água e $135 \mathrm{~g}$ de ureia, o equivalente a $100 \mathrm{~L}$ de água e $22,5 \mathrm{Kg}$ de ureia por hectare.

A cultivar utilizada foi a Desafio RR da empresa Brasmax ${ }^{\circledR}$, de hábito de crescimento indeterminado, exigente em alta fertilidade do solo, resistente ao acamamento e à doença olho de rã, causada pela Cercospora sojinia. Seu ciclo é considerado semiprecoce de 112 a 125 dias segundo especificações do distribuidor. Utilizou-se uma população de 20 plantas por metro com o intuído de se obter uma densidade de 380 mil plantas finais por hectare.

Os tratos culturais foram realizados pelo produtor conforme exigência da cultura de soja. Para controle da ferrugem, realizaram-se quatro aplicações de fungicida do grupo químico (Estrobirulina e Triazol) e (Trifloxistrobina e Protioconazole), junto com a segunda aplicação de fungicida, foi incorporada à calda, uma dose de Mn, Mo como adubação foliar.

As avaliações se iniciaram no início do enchimento de grãos $\left(\mathrm{R}_{5}\right)$, avaliando-se a clorofila total, massa seca da parte aérea, área foliar e número de folhas. As avaliações da fase reprodutiva foram avaliadas ao final do enchimento de grãos $\left(\mathrm{R}_{6}\right)$, considerando nesta fase o número de nódulos, massa seca de nódulos, massa seca de raízes, diâmetro do caule e altura de plantas. Os componentes de produção foram avaliados no ato da colheita $\left(R_{9}\right)$, nesta fase avaliou-se $o$ número de grãos por vagem, número de vagens por plantas, massa de mil grãos, grãos por vagens e produtividade, com amostras de quatro plantas por parcela útil para cada fase.

A altura de plantas foi obtida, ainda em campo, com auxílio de uma trena, medindo-se do solo até o meristema apical das plantas. Após as medições a campo, as plantas foram cortadas rente ao solo, acondicionadas em sacos de papel e levadas ao laboratório de sementes da UFMT, campus Sinop.

No laboratório, foi determinada a da área foliar $\mathrm{em}^{2}$, com auxílio de um integrador de área foliar LICOR modelo (LI-3010), os nódulos foram contados, e o diâmetro de caule medido com o auxílio de um paquímetro. Por fim, para obter a massa seca de parte aérea e dos nódulos, as amostras foram acondicionadas em sacos de papel e levadas para a estufa de circulação forçada com temperatura de $65^{\circ} \mathrm{C}$ até peso constante.

A colheita foi realizada manualmente e, após o arranquio, fez-se a contagem do número de vagens e do número de grãos por vagem. As plantas colhidas foram, então, trilhadas com o auxílio de uma trilhadora estacionária motorizada no 
local do experimento e os grãos acondicionados em sacos de papel devidamente identificados. O material foi conduzido até o laboratório de sementes na Universidade Federal de Mato Grosso, onde foi peneirado manualmente para retirar as impurezas, logo em seguida colocado em estufa de circulação forçada de ar, a $60^{\circ} \mathrm{C}$, até atingir umidade relativa de $130 \mathrm{~g} \mathrm{~kg}^{-1} \mathrm{de}$ água. Em seguida, foi feita a contagem dos grãos para se determinar o peso de mil grãos (PMG) e produtividade por parcela, calculada $\mathrm{em} \mathrm{Kg} / \mathrm{ha}$.

Os dados obtidos foram submetidos à análise de variância (ANOVA), ao nível de 5\% de probabilidade pelo teste F, com o auxílio do programa estatístico GENES (CRUZ, 2017). As médias foram comparadas pelo teste de Tukey a $5 \%$ de probabilidade.

\section{RESULTADOS}

As avaliações realizadas no início do enchimento de grãos $\left(\mathrm{R}_{5}\right)$ na parte aérea das plantas (Tabela 2) apresentaram diferenças que foram significativas a $5 \%$. Verificou-se que as variáveis: clorofila, massa seca da parte aérea, área foliar e número de folhas foram significativamente influenciados pelos tratamentos.

Tabela 2. Médias das variáveis analisadas início do enchimento de grãos $\left(\mathrm{R}_{5}\right)$ : clorofila total (CLO), massa seca da parte aérea (MSPA), área foliar $(\mathrm{AF})$ e número de folhas $(\mathrm{NF})$, sob diferentes formas e épocas de aplicação de $10 \mathrm{~kg} \mathrm{ha}^{-1}$ de nitrogênio. UFMT. Safra 2018/2019, Sinop - MT.

Table 2. Averages of the analyzed variables start of grain filling (R5): total chlorophyll (CLO), dry mass of the aerial part (MSPA), leaf area $(\mathrm{AF})$ and number of leaves $(\mathrm{NF})$, under different forms and times of application of $10 \mathrm{~kg} \mathrm{ha}^{-1}$ of nitrogen. UFMT. 2018/2019 harvest, Sinop - MT.

\begin{tabular}{|c|c|c|c|c|c|c|c|c|}
\hline Trat. & \multicolumn{2}{|c|}{ CLO } & \multicolumn{2}{|c|}{ MSPA } & \multirow{2}{*}{\multicolumn{2}{|c|}{$\frac{\mathrm{AF}}{1201, \quad \mathrm{~b}}$}} & \multicolumn{2}{|c|}{$\mathrm{NF}$} \\
\hline Sem & 29,7 & $\mathrm{a}$ & 51,42 & $a b c$ & & & 37,5 & bcd \\
\hline $\mathrm{N}$ & 27,8 & $a b$ & 50,71 & $\mathrm{bc}$ & 1247, & $\mathrm{b}$ & 41,5 & $\mathrm{~b}$ \\
\hline $\mathrm{N}$ & 28,1 & $a b$ & 53,14 & $a b$ & 1489, & a & 40,2 & $\mathrm{bc}$ \\
\hline $\mathrm{N}$ & 29,3 & a & 54,23 & a & 1457, & $\mathrm{a}$ & 48,0 & a \\
\hline $\mathrm{N}$ & 29,7 & a & 50,83 & $a b c$ & 1193, & b & 41,5 & $\mathrm{~b}$ \\
\hline $\mathrm{N}$ & 26,1 & $\mathrm{~b}$ & 50,27 & bcd & 1102, & b & 38,5 & $\mathrm{bc}$ \\
\hline $\mathrm{N}$ & 30,7 & a & 48,71 & $\mathrm{~cd}$ & 1088, & c & 41,0 & $\mathrm{bc}$ \\
\hline $\mathrm{N}$ & 30,4 & a & 47,19 & $\mathrm{~d}$ & 1077, & c & 33,0 & $\mathrm{~d}$ \\
\hline $\mathrm{N}$ & 30,2 & $\mathrm{a}$ & 48,60 & $\mathrm{~cd}$ & 1130, & $\mathrm{b}$ & 36,0 & $\mathrm{~cd}$ \\
\hline DM & 2,99 & & 3,50 & & 153,5 & & 5,28 & \\
\hline CV( & 4,28 & & 2,88 & & 5,23 & & 5,53 & \\
\hline
\end{tabular}

*As médias seguidas das mesmas letras não diferem entre si ao nível de $5 \%$ de probabilidade pelo teste de Tukey.

Com as comparações estatísticas pelo teste de média Tukey (5\%), observaram-se resultados significativos na fase $\mathrm{V}_{6}$ de aplicação do nitrogênio para as variáveis analisadas no início do enchimento de grãos (Tabela 2). Para a clorofila e a massa seca da parte aérea não foram observadas significâncias quando comparadas à testemunha; a área foliar e o número de folhas tiveram resultados significativos e os maiores valores ocorreram no estádio $V_{6}$ para todas as características avaliadas nessa fase.

Para as variáveis relacionadas ao sistema radicular (Tabela 3) observou-se que os tratamentos alteraram significativamente o número de nódulos, a massa seca de nódulos, a massa seca de raízes. No diâmetro do caule e na altura de plantas, o mesmo resultado não foi obtido, mostrando não terem ocorrido diferenças entre estas características. O número de nódulos (Tabela 3) foi maior quando se aplicou nitrogênio nas fases iniciais e finais das plantas, embora tenha sido na fase $R_{3}$ que todas as características radiculares tiveram semelhanças ao atingirem o melhor aproveitamento da aplicação do $\mathrm{N}$ foliar.

$\mathrm{Na}$ massa seca de raízes, ocorreram os melhores resultados com a aplicação em $\mathrm{V}_{6}$, também observado no número de folhas e na área foliar, mostrando uma relação entre o crescimento radicular e esse crescimento radicular ocorre quando melhor se desenvolve a parte aérea. Entretanto, essa relação entre o crescimento radicular e a parte aérea não foi observada no número de nódulos por planta, o qual teve melhores resultados quando aplicados ao final da fase reprodutiva ou na testemunha.

Tabela 3. Médias das variáveis analisadas ao final do enchimento de grãos $\mathrm{R}_{6}$ : número de nódulos $\left(\mathrm{N}^{\circ} \mathrm{N}\right)$, massa seca de nódulos (MSN), massa seca de raízes (MSRAIZ), diâmetro do caule (DC) e altura de plantas (ALT), sob diferentes formas e épocas de aplicação de $10 \mathrm{~kg}$ ha $^{-1}$ de nitrogênio. UFMT. Safra 2018/2019, Sinop - MT.

Table 3. Averages of the variables analyzed at the end of R6 grain filling: number of nodules (No.N), dry mass of nodules (MSN), dry mass of roots (MSRAIZ), stem diameter (DC) and plant height (ALT ), under different forms and times of application of $10 \mathrm{~kg} \mathrm{ha}$ ${ }^{1}$ of nitrogen. UFMT. 2018/2019 harvest, Sinop - MT.

\begin{tabular}{lrlrlllllll}
\hline Trat. & $\mathrm{N}^{\circ} \mathrm{N}$ & \multicolumn{2}{c}{ MSN } & \multicolumn{2}{c}{ MSRAIZ } & \multicolumn{1}{c}{ DC } & \multicolumn{2}{c}{ ALT } \\
\hline Sem N & 22 & ab & 0,3 & bcd & 4,79 & e & 0,67 & a & 0,98 & a \\
$\mathrm{N} \mathrm{V}_{2}$ & 21,7 & abc & 0,25 & de & 5,37 & bcd & 0,75 & a & 0,97 & a \\
$\mathrm{N} \mathrm{V}_{4}$ & 17,7 & bcd & 0,28 & cde & 5,58 & abc & 0,75 & a & 1,01 & a \\
$\mathrm{N} \mathrm{V}_{6}$ & 16,2 & d & 0,35 & ab & 6,05 & a & 0,75 & a & 0,99 & a \\
$\mathrm{N} \mathrm{V}_{8}$ & 15,2 & d & 0,33 & abc & 5,16 & cde & 0,7 & a & 0,98 & a \\
$\mathrm{N} \mathrm{R}_{1}$ & 18,2 & bcd & 0,27 & cde & 5,46 & bc & 0,65 & a & 0,93 & a \\
$\mathrm{N} \mathrm{R}_{2}$ & 17,5 & cd & 0,25 & de & 4,81 & de & 0,7 & a & 0,95 & a \\
$\mathrm{N} \mathrm{R}_{3}$ & 19,2 & abcd & 0,22 & e & 4,82 & de & 0,62 & a & 0,97 & a \\
$\mathrm{N} \mathrm{R}_{4}$ & 23 & a & 0,37 & a & 5,79 & ab & 0,67 & a & 0,98 & a \\
\hline DMS & 4,39 & & 0,64 & & 0,56 & & 0,24 & & 0,12 & \\
CV $(\%)$ & 9,62 & & 8,99 & & 4,4 & & 14,1 & & 5,2 & \\
\hline
\end{tabular}

* Médias seguidas por uma mesma letra, em cada coluna, não diferem estatisticamente (Tukey, $\mathrm{p}>0,05)$.

$\mathrm{Na}$ avaliação da fase de colheita $\left(\mathrm{R}_{8}\right)$ para os componentes de produtividade (Tabela 4), percebeu-se que a aplicação de $\mathrm{N}$ teve os maiores valores quando aplicado no estádio $\mathrm{V}_{2}$ para as características do número de grãos por vagens e número de vagens por planta. Esses valores refletiram em melhor produtividade com base nessas duas características, embora na avaliação das demais características, a fase $\mathrm{V}_{6}$ obteve melhores resultados.

Com as tabelas mostradas nos componentes vegetativos e na produção, a fase $\mathrm{V}_{6}$ foi muito eficiente no desenvolvimento vegetativo. No entanto, apresentou a menor quantidade de grãos por vagens, comprometendo o resultado produtivo, que poderia proporcionar, na fase $\mathrm{V}_{2}$, $\mathrm{O}$ uso de nitrogênio foi mais efetivo, o que acarretou em produção final de grãos.

\section{DISCUSSÃO}

$\mathrm{O} \mathrm{N}_{2}$ é encontrado na atmosfera na sua forma mais estável em grande quantidade, mas essa forma não pode ser utilizada pelas plantas para sua nutrição, pois não consegue formar moléculas de fotoassimilados, a não ser que ocorra a redução do $\mathrm{N}_{2}$ atmosférico a $\mathrm{N}$-amoniacal. Somente pode ser realizada a conversão de duas alternativas do nitrogênio molecular $\left(\mathrm{N}_{2}\right)$ em amônia $\left(\mathrm{NH}_{3}\right)$, pela forma química de 
fixação na indústria e pelas bactérias na fixação biológica do nitrogênio (ALCANTARA; REIS, 2008).

Tabela 4. Médias das variáveis analisadas na colheita R9: número de grãos por vagem ( $\mathrm{N}^{\circ} \mathrm{G} / \mathrm{V}$ ), número de vagens por plantas (VAG.), massa de mil grãos (M1000G), grãos por vagens (GPV) e produtividade (PROD.), sob diferentes formas e épocas de aplicação de $10 \mathrm{~kg} \mathrm{ha}^{-1}$ de nitrogênio. UFMT. Safra 2018/2019, Sinop - MT.

Table 4. Averages of the variables analyzed in the $\mathrm{R} 9$ harvest: number of grains per pod (No. G / V), number of pods per plant (VAG.), Mass of a thousand grains (M1000G), grains per pod (GPV) and productivity (PROD.), Under different forms and times of application of $10 \mathrm{~kg} \mathrm{ha}^{-1}$ of nitrogen. UFMT. 2018/2019 harvest, Sinop - MT.

\begin{tabular}{lrlllrlll}
\hline Trat. & \multicolumn{2}{c}{$\mathrm{N}^{\circ}$ G/V } & \multicolumn{2}{l}{ VAG. } & \multicolumn{2}{c}{ M1000G } & \multicolumn{2}{c}{ PRO } \\
\hline Sem N & 2,22 & ab & 32,3 & bc & 157,05 & ab & 3732 & ab \\
N V2 & 2,27 & ab & 33,3 & ab & 155,27 & b & 3877 & a \\
N V4 & 1,9 & bc & 34,5 & ab & 155,77 & ab & 3370 & c \\
N V6 & 1,7 & c & 38,5 & a & 156,07 & ab & 3405 & c \\
N V8 & 1,87 & bc & 34,5 & ab & 160,45 & a & 3512 & bc \\
N V10 & 1,95 & bc & 33,0 & b & 158,22 & ab & 3347 & c \\
N V12 & 2,27 & ab & 30,0 & bc & 156,40 & ab & 3564 & bc \\
N R1 & 2,37 & a & 27,0 & c & 157,62 & ab & 3369 & c \\
N R3 & 2,12 & ab & 32,8 & b & 154,67 & b & 3536 & bc \\
\hline DMS & 0,41 & & 5,48 & 5,002 & & 0,25 & \\
CV $(\%)$ & 8,22 & 6,94 & 1,33 & 2,97 &
\end{tabular}

* Médias seguidas por uma mesma letra, em cada coluna, não diferem estatisticamente (Tukey, $\mathrm{p}>0,05)$.

O uso de nitrogênio foliar nos estágios fenológicos reprodutivos contribui para o incremento na produtividade, pois os nódulos das plantas já estão diminuindo sua atividade de fixação do nitrogênio para as plantas (FANCELLI, 2014). Nesta pesquisa, utilizou-se esse elemento, nas fases vegetativas da cultura, para verificar a ocorrência de alterações nas características fisiológicas da planta, para, assim, obter o incremento produtivo favorável.

Com os resultados Tabelas 2, 3 e 4, verificou-se que as plantas com maior número de folhas também apresentaram maiores valores de massa seca de parte área, número de folhas e raízes, embora não tenham obtido maior resposta produtiva. No entanto, essas características foram determinantes para o acúmulo de matéria seca da planta.

O suprimento de nutrientes em quantidades ou fases inadequadas pode produzir efeitos negativos nas plantas (FANCELLI, 2014). Em assim sendo, as doses e fases realizadas na cultura via foliar exercem somente a função fisiológica, não sendo considerada nutricional, o que mostrou nos resultados desta pesquisa efeitos negativos na produção quando foi utilizado o $\mathrm{N}$ depois que os nódulos estavam ativos.

Ao avaliar o número de nódulos (Tabela 3), a aplicação na última fase da avaliação $\left(\mathrm{R}_{2}\right)$ atingiu maior peso, mesmo quando se verificou ser estatisticamente igual aos demais tratamentos da fase inicial e a testemunha, Também se verificou o aumento na massa seca de nódulos, na época de maior exigência nutricional da planta para o enchimento de grãos. Nessa fase, o $\mathrm{N}$ proporcionou melhor resposta pela baixa atividade dos nódulos, que ocorrem nas fases iniciais e finais da cultura, condição para suprir necessidades pontuais dessa etapa e que, provavelmente, o $\mathrm{N}$ aplicado nesse período foi responsável pelo ganho de massa dos nódulos, condição em que poderia ocorrer danos na fisiologia, como os relatados por Fancelli (2014).

Muitos agricultores, visando obter maiores rendimentos, colocam doses mais elevadas de fertilizantes nitrogenados, de até $150 \mathrm{~kg}$ de N/ha, parcelados em duas vezes (HUNGRIA, 1997). Contudo, como o fertilizante inibe o processo biológico, a nodulação da soja, e a adição de $\mathrm{N}$ não causa qualquer incremento nos rendimentos da cultura (MENDES, et al., 2008). Nesta pesquisa, utilizaram-se doses via foliar e com baixa quantidade, e, nessa condição, o $\mathrm{N}$ tem a função fisiológica na planta. Desta forma, o nutriente não possui concentração suficiente para inibir o processo fisiológico.

As variáveis de diâmetro do caule e da altura das plantas não foram influenciadas pelos tratamentos, essa influência só ocorreria com a aplicação de grandes quantidades de $\mathrm{N}$. Como fonte nutricional complementar o recomendado para se utilizar o $\mathrm{N}$ é de 15 a $20 \mathrm{Kg} / \mathrm{ha}$ (FANCELLI, 2014; CÂMARA, 2014), condição que não era o objetivo desta pesquisa.

Outros estudos afirmam que a leguminosa possui alta capacidade de fixação de $\mathrm{N}_{2}$, durante seu ciclo de vida podendo atingir entre 285 a $325 \mathrm{Kg} / \mathrm{ha} \mathrm{N}$ com nodulação adequada, sendo capaz de apresentar produções de até $4 \mathrm{t} / \mathrm{ha}$, sem o uso de fertilizantes nitrogenados (BODDEY et al., 1990; HUNGRIA et al., 2006; CÂMARA, 2014; FANCELLI 2014).

A aplicação de nitrogênio na fase inicial $\left(V_{2}\right)$ e a testemunha foram os dois tratamentos que atingiram as maiores produtividades (Tabela 4), iguais estatisticamente.

Como a quantidade foi com efeitos fisiológicos, os nódulos não estavam ativos. $\mathrm{Na}$ fase inicial, foi responsiva a cultura, na testemunha, porque não ocorreu interferência externa N. Os nódulos foram suficientes para suprir a demanda das plantas, condição esta que não se manteve nas aplicações posteriores.

Embora seja significativo o valor em reais, quando se obteve uma diferença entre a testemunha e a fase $V_{2}$, obtevese também um incremento de $145 \mathrm{Kg} /$ ha. A soja, no médio norte, na linha da BR 163, normalmente é negociada por $\mathrm{R} \$ 60,00$ a saca, com um custo médio de $\mathrm{R} \$ 1,2$ o Kg da Uréia. Foram utilizados $22,5 \mathrm{Kg}$ do insumo, neste cenário, acrescentando os custos com máquinas para a pulverização em torno de $\mathrm{R} \$ 12,00 /$ ha seria de $\mathrm{R} \$ 106,00$ o incremento financeiro por ha, condição que não é viável realizar aplicação nessas condições e com base nas demais variáveis que fizeram parte da pesquisa.

$\mathrm{Na}$ avaliação das demais características (Tabelas 2, 3 e 4), elas não são favoráveis como fator indicativo na manutenção se utilizadas nas lavouras comerciais, além das variáveis climáticas, como os veranicos e baixa luminosidade, possíveis de ocorrer, podendo ser favoráveis ou não à manutenção dos resultados.

A fase crítica de desenvolvimento da planta é o período em que os nutrientes são absorvidos em maior quantidade. Nessa fase, as plantas apresentam uma maior exigência nutricional, e correspondem aos estádios reprodutivos. Nesta pesquisa, o incremento ocorreu quando aplicado antes do início das atividades dos nódulos $\left(\mathrm{V}_{2}\right)$. Porém continua intensa a demanda por nutrientes durante a floração e início de enchimento de grãos, porque, nessa fase, também, ocorre uma elevação na taxa de translocação dos nutrientes pela planta.

O uso de $\mathrm{N}$, quando avaliado no componente radicular, a melhor resposta ocorreu nas fases finais do vegetativo, 
tendência que só não se manteve para o número de nódulos, os quais obtiveram melhores respostas nas fases iniciais e finais do ciclo de vida da planta, o que também coincide com a época de sua menor efetividade de fixação; nas demais fases, foi prejudicial.

\section{CONCLUSÕES}

As variáveis fisiológicas na parte aérea e radicular da planta obtiveram melhores resultados quando aplicado o $\mathrm{N}$ na fase vegetativa, condição que melhorou a eficiência no crescimento, no entanto não obteve resposta produtiva nessa fase.

Nos componentes de produção, obtêm-se resultados produtivos com aplicação de $\mathrm{N}$, a fase $\mathrm{V}_{2}$, antes dos nódulos tornaram-se ativos na fixação do nitrogênio, contribuindo para o desenvolvimento inicial das raízes e nodulação posterior.

A eficácia da aplicação nitrogenada depende de fatores econômicos, entretanto, avaliando todos os aspectos ligados à planta, observou-se que eles não são suficientes financeiramente para sua utilização.

\section{REFERÊNCIAS}

ALCANTARA, R. M. C. M.; REIS, V. M. Metabolismo do carbono nos nódulos. Seropédica: Embrapa Agrobiologia, 2008. 32 p.

BODDEY, R. M.; URQUIAGA, S.; PERES, J. R.; SUHET, A. R.; NEVES, M. C. P. Quantification of the contribution of $\mathrm{N} 2$ fixation to field-grown legumes: a strategy for the practical application of the $15 \mathrm{~N}$ isotope dilution technique. Soil Biology and Biochemistry, Elmsford, v. 22, n. 5, p. 649-655, 1990. DOI: https://doi.org/10.1016/0038-0717(90)90011-N

CÂMARA, G. M. S. Fixação biológica de nitrogênio em soja. Informações agronômicas, n. 147, p. 1-9, 2014.

CONAB. COMPANHIA NACIONAL DE ABASTECIMENTO. Produção de grãos cresce 3,4\% e chega a 235,3 milhões de toneladas. Brasília: Companhia Nacional de Abastecimento. 2019. Disponível em: <https://www.conab.gov.br/ultimasnoticias/2845-producao-de-graos-cresce-3-4-e-chega-a235-3-milhoes-de-toneladas >. Acesso em: 02 Mai. 2019.

CRISPINO, C. C.; FRANCHINI, J. C.; MORAES, J. J.; RUBSON N. R.; SIBALDELLE R. N. R.; LOUREIRO, M. F.; SANTOS, E. N.; CAMPO, R. J.; HUNGRIA, H. Adubação nitrogenada na cultura da soja. Londrina: Embrapa Soja, 2001. 6 p. (Comunicado técnico, 75).
CRUZ, C.D. Programa Genes - Aplicativo computacional em genética e estatística. Versão 2017. Disponível em: <www.ufv.br/dbg/genes/genes.htm>. Acesso em: 2 fev. 2019.

EMBRAPA_ EMPRESA BRASILEIRA DE PESQUISA AGROPECUÁRIA. Sistema Brasileiro de Classificação de Solos. 5. ed. Brasília: Embrapa, 2018. $356 \mathrm{p}$.

FANCELLI, A. L. Inovações tecnológicas no sistema de produção Soja-Milho. Piracicaba: USP/ESALQ/LPV, 2014. 176 p.

HUNGRIA, M.; CAMPO, R. J.; MENDES, I. C.; GRAHAM, P. H. Contribution of biological nitrogen fixation to the $\mathrm{N}$ nutrition of grain crops in the tropics: the success of soybean (Glycine max (L.) Merr.) in South America. In: SINGH, R. P.; SHANKAR, N.; JAIWAL, P. K. (Eds.). Nitrogen nutrition in plant productivity. Houston: Studium Press, 2006. p. 43-93.

HUNGRIA, M.; CAMPO, R. J.; MENDES, I. C. A importância do processo de fixação biológica do nitrogênio para a cultura da soja: componente essencial para a competitividade do produto brasileiro. Londrina: Embrapa Soja/Embrapa Cerrados, 2007. 80 p.

HUNGRIA, M.; VARGAS, M. A. T.; CAMPOS, R. J., GALERANI, P. R. Adubação nitrogenada na soja. Embrapa soja: Londrina, 1997. 4 p.

HUNGRIA, M.; CAMPO, R. J.; MENDES, L. de C. Fixação biológica do nitrogênio na cultura da soja. Londrina: Embrapa Soja, 2001. 48 p.

MENDES, I. C.; JUNIOR, F. B. R.; HUNGRIA, M.; SOUSA, D. M. G.; CAMPO, R. J. Adubação nitrogenada suplementar tardia em soja cultivada em latossolos do Cerrado. Pesquisa Agropecuária Brasileira, Brasília, v. 43, n. 8, p. 1053-1060, 2008. DOI: http://dx.doi.org/10.1590/S0100-204X2008000800015

PÍPOLO, A. E.; HUNGRIA, M.; FRANCHINI, J. C.; JUNIOR, A. A. B.; DEBIASI, H.; MANDARINO, J. M.G. Teores de óleo e proteína em soja: fatores envolvidos e qualidade para a indústria. Londrina: Embrapa soja, 2015. 16 p.

SFREDO, G. J.; OLIVEIRA, M. C. N. de. Soja: molibdênio e cobalto. Londrina: Embrapa Soja, 2010. 36 p.

SOUZA, A. P.; MOTA, L. L.; ZAMADEI, T.; MARTIM, C. C.; ALMEIDA, F. T.; PAUlinO, J. Classificação climática e balanço hídrico climatológico no estado de Mato Grosso. Nativa, Sinop, v. 1, n. 1, p. 34-43, 2013. DOI: http://dx.doi.org/10.14583/2318- 